\title{
LIMITES DO EU: O GESTO AUTOBIOGRÁFICO NO CINEMA DE JEAN EUSTACHE
}

\section{ROMERO FIDELIS DE SOUZA MACIEL}

Universidade Federal de Ouro Preto

O presente artigo visa analisar o gesto autobiográfico nas narrativas cinematográficas de Jean Eustache. Dono de uma série de experimentos que vão de curtas metragens, passando pelo documentário, até longas de ficção, o autor em questão, ao mesmo tempo em que se insere na linhagem das narrativas ditas autobiográficas, rompe com o princípio de sistematização do eu em sua filmografia, pulverizando-o em filmes de dicção variada, embaralhando gêneros, de forma que fique a cargo do espectador o trabalho de construir a teia de referências autobiográficas. Por mais que isso seja um atestado de caos, pela falta de unidade em sua obra, é interessante perceber como o seu cinema aponta para uma subjetividade que prefere converter sua própria fragmentação numa assinatura estilística consciente. Entender de que maneira Eustache se representa no campo da autobiografia, ao colocar à prova suas fronteiras, é o propósito dessa análise.

Palavras-chave: Narrativa. Cinema. Autobiografia.

THE LIMITS OF THE SELF: THE AUTOBIOGRAPHIC GESTURE IN THE CINEMA OF JEAN EUSTACHE

The present article aims to analyze the autobiographic gesture in the cinematographic narratives of Jean Eustache, an author who experimented with short films, documentaries, as well as fiction feature films. At the same time that Eustache fits into the lineage of the socalled autobiographical narratives, in his filmography he also breaks with the principle of systematization of the self, spreading it in films with diverse diction and muddling different kinds of gender, so it is up to the spectator to build the web of autobiographic references. Even though this may be regarded as a statement of chaos, due to the lack of unity in his work, it is interesting to note how his cinema points to a subjectivity that prefers to convert its own fragmentation into a conscious stylistic signature. The present analysis aims to understand the way Eustache represents himself in the field of autobiography by testing his own frontiers.

Keywords: Narrative. Cinema. Autobiography. 


\section{RESUMEN LIMITES DEL YO: EL GESTO AUTOBIOGRÁFICO EN EL CINE DE JEAN EUSTACHE}

El presente artículo pretende analizar el gesto autobiográfico en las narrativas cinematográficas de Jean Eustache. Dueño de una serie de experimentos que van desde cortometrajes, pasando por los documentales, hasta largometrajes de ficción, el autor en cuestión, al mismo tiempo en que se inserta en el linaje de narrativas autobiográficas, rompe con el principio de sistematización del yo en su filmografía, pulverizándolo en películas de dicción variada, mezclando géneros, de manera que quede a cargo del espectador el trabajo de construir la red de referencias autobiográficas. Aunque esto sea una comprobación de caos, por la falta de unidad en su obra, es interesante percibir como su cine apunta para una subjetividad que prefiere convertir su propia fragmentación en una firma estilística consciente. Entender de qué manera Eustache se representa en el campo de la autobiografia, al poner a prueba sus fronteras, es el propósito de este análisis.

Palabras clave: Narrativa. Cine. Autobiografía.

Se me interponho, sou dúplice de mim mesmo: Não posso ser o meu próprio intérprete.

Nietzsche (2000, p. 22)

Um dos temas mais recorrentes na arte do pós-guerra é a análise do comportamento da juventude e a sua forma de estar no mundo frente às mudanças socioculturais desse período em diante. Neste campo, o cinema moderno, assim como o rock, pode ser visto como uma das principais expressões artísticas da revolução de costumes, por refletir sentimentos subversivos, em vários âmbitos da sociedade, de questões políticas aos valores sexuais e morais de classes. Canalizando críticas a esses valores e beneficiando-se da experimentação estética dos cinemas novos pelo mundo, encabeçados por figuras como Antonioni e Godard, essa arte testemunharia uma das mais proficuas décadas de experimentação de sua história.

Nessa perspectiva, está um dos diretores mais celebrados, surgido logo após a explo- são da Nouvelle Vague francesa: Jean Eustache (1938-1981). Seus filmes, de alguns anos para cá, tornaram-se presença constante nas listas das obras mais importantes do cinema moderno, visto em revistas como Cahiers du cinéma e Sight and sound. Natural do interior da França, da pequena cidade de Pessac, o diretor em questão, assim como muitos aspirantes a jovens cineastas dessa época, obteve no cinema a formação autodidata necessária para começar a rodar seus primeiros curtas. Com uma carreira que compreende 12 filmes, alternando entre documentários e ficções, esse realizador é visto pela crítica como típico representante da segunda geração da Nouvelle Vague francesa, ao lado de nomes como Philippe Garrel, Maurice Pialat e Chantal Akerman.

Mais do que apresentar apenas uma assinatura estilística, como, por exemplo, as montagens sincopadas de Godard e o seu gosto pela citação a outras obras do cinema, em Eustache há uma impregnação de recortes das mais variadas estéticas do cinema moderno. De fato, 
percebemos que, na maioria dos seus filmes, há uma forte influência de realizadores como Robert Bresson, Mizoguchi e Rohmer, dando a impressão de guiar o ritmo estilístico da narrativa em tonalidades oscilantes. No entanto, nenhum dispositivo estético desses autores se sobressai, uma vez que todos se encontram diluídos e retrabalhados na organicidade singular de sua obra.

Um dos assuntos que mais chama a atenção nos seus trabalhos são os impactos das transformações socioculturais desse período, cujo foco girava em torno das inadequações de jovens em formação e seus comportamentos imprevisíveis. À guisa de ilustração, podemos reconhecer esses aspectos, na sequência inicial de Du côté de Robinson (1963), na qual vemos dois amigos jogando fliperama e conversando num café parisiense. Lá, eles fazem planos e estudam qual o melhor lugar de Paris para conhecer garotas, e entre ideias discordantes sobre qual o melhor bairro, saem do café e perambulam, ao sabor da sorte, pelos bulevares. Nas cenas que seguem, os dois, pelo grande centro, abordam, sem maiores dificuldades, uma garota que vai se divertir num clube de dança. Nesse meio tempo, a conversa deles gira em torno das relações amorosas. A cada virada de esquina, o papo vai se tornando cada vez mais crispado e agressivo até se transformar num verdadeiro interrogatório construído a partir de uma mise-en-scène que lembra Godard em Masculin-Feminin (1966). Neste, Paul, ao convidar Madeleine para sair, inicia um longo diálogo cheio de flertes, evidenciando aos poucos as contradições ideológicas dessa juventude reconhecida no filme como "filhos de Marx e da Coca-Cola". Em Eustache, por sua vez, pelo discurso da jovem, os fatos de sua vida vão se desdobrando: ela, separada recentemente, diz que não pretende voltar a morar com os pais, preferindo viver por conta própria e criar dois filhos, ao mesmo tempo em que procura um emprego. Contudo, não abre mão da liberdade de sair para se divertir. Reclama que hoje em dia os homens não sabem abordar uma mulher e começa a relatar, num tom impassivel, as últimas tentativas fracassadas que outros rapazes usaram para conquistá-la. Tal situação frustra os dois jovens que acabam perdendo o interesse nela.

A partir da disposição dessa sequência, podemos perceber uma das características centrais da narrativa de Eustache: o interesse em observar como a juventude reage numa época em que velhos padrões e valores instituídos são a todo momento colocados em xeque. Preferindo passar a maior parte do tempo nas ruas, seduzidos pela nova aura de liberdade que a cultura de massa proporciona, esses jovens buscam preencher o tempo vago construindo relações de flertes e aproximações que têm na efemeridade a sua principal característica. Eustache, assim como Godard, faz um estudo antropológico de uma geração. A cada filme apresentado, é possível analisar como as tendências que surgiam no âmbito da juventude eram substituídas umas pelas outras, desde regras ditadas pela sociedade de consumo, passando pelas práticas culturais, até a revolta juvenil à beira do Maio de 68 .

Nesse meio tempo, era natural que movimentos contraculturais surgissem, direcionando novos caminhos, contestando e transgredindo limites estabelecidos da geração anterior, seja através da arte ou pelo caráter político. Um exemplo paradigmático disso é o que Baecque (2010) coloca em relevo, ao mostrar como se deu o surgimento da cinefilia e a inclinação dos jovens críticos de revistas sobre cinema, como Positif e Cahiers du cinéma, que rompiam com a "tradição de qualidade" do cinema francês. Tradição que, denunciada pelos redatores mais engajados da época, remetia a adaptações diretas de romances clássicos, de Stendhal e André Gide, ou filmes de fór- 
mula pronta para circular na grande indústria. Na contramão dessa tendência, e sob a égide da "política dos autores", que dava status de grandes artistas a diretores tidos como comerciais (Hawks e Hitchcock), cineastas como Godard, Truffaut e Chabrol estavam construindo aos poucos, através de seus escritos, seu próprio movimento: a Nouvelle Vague francesa, movimento cuja principal linha de força se concentrava em novas propostas de se fazer e pensar o cinema. Ao ressaltar a importância da assinatura estilística, em filmes narrados de maneira raramente impessoal, além de priorizar experimentações, liberdade narrativa, pesquisas referenciais, tanto no cânone quanto na vanguarda, esses jovens diretores conquistaram sua própria visão de mundo e finalmente a soberania de dizer "eu".

Suas críticas, disseminadas principalmente pelo carro-chefe dessa cinefilia, a saber, a revista Cahiers du cinéma, direcionavam o olhar do leitor para um aspecto até então pouco explorado: o trabalho da mise-en-scène cinematográfica. Funcionado muito mais do que um instrumento do autor, seja pela maneira de organizar a cena, ou regular aspectos técnicos da filmagem, esse dispositivo estaria associado ao conjunto de possibilidades que dá forma e pensamento ao filme. Análogo ao trabalho literário, esses diretores refinavam uma espécie de escrita a partir de seu roteiro, pelo arranjo da cena, e, sobretudo pela câmera. Por esse motivo, ao analisar a mise-en-scène, os críticos mostrariam como cada diretor seria detentor de uma assinatura estilística própria do textofílmico, categorizando-o como o autor por trás da obra.

A partir dessa configuração, a crítica do pós-guerra assume uma nova postura perante as análises do seu objeto, ou seja, um trabalho mais refinado, de artesão, que cruza fontes e satura o filme com interpretações das mais variadas, na tentativa de montar um autorretrato do autor, reconhecendo-o como uma persona detentora de um olhar particular do próprio cinema, em sua totalidade. Nessa obsedante pesquisa, a fim de construir o mito do autor por trás da obra, muitas vezes o itinerário do crítico esbarrava em aspectos autobiográficos, ao enxergar a obra em sincronia com a biografia do seu objeto. Não por acaso, é um aspecto presente nas análises do crítico-cineasta Luc Moullet (2000) até estudos mais detidos como o de Alain Philippon (2005), ao colocarem em questão o princípio criativo de Jean Eustache. No ensaio elegíaco sobre Eustache, após o seu suicídio, Moullet (2000) analisa como cada filme é uma rememoração de momentos pontuais de sua formação - de como um garoto comum da província se converteu num dândi frequentador dos bares da moda de Montparnasse. Philippon (2005), por sua vez, além de sugerir que sua filmografia seja de cunho abertamente autobiográfico, sinaliza para um trabalho em progresso de refinamento narrativo. A recuperação do seu passado, funcionando para o crítico como uma espécie de Em busca do tempo perdido, sinaliza não só traços autobiográficos, mas insinua uma espécie de síntese que encapsula e retoma outras imagens do cinema moderno.

Por esse motivo, é curioso perceber como sua mise-en-scène, aos poucos, parece ecoar segmentos de filmes de outros diretores, assim como outros personagens para complementar sua própria história. Em Le père Noël a les yeux bleus (1966), por exemplo, no qual o foco narrativo seria um recorte de sua adolescência sem dinheiro e sem trabalho, pelas ruas de Narbonne, podemos ler algumas cenas como se fosse um espelhamento de Os incompreendidos (1959). Enquanto o adolescente de Truffaut rouba uma máquina de escrever para penhorar, Daniel (alter ego de Eustache), por sua vez, rouba livros numa livraria para vendê-los e pagar entradas no cinema. As semelhanças 
se tornam mais evidentes se considerarmos o fato de que Jean Pierre Leáud parece prolongar o seu personagem de Os incompreendidos, cujo modelo comportamental em Le père Noël é um desdobramento natural de sua atuação no primeiro longa de Truffaut. Outro diretor que pode ser lido na narrativa eustachiana é Eric Rohmer. Em A mãe e a puta (1973), no momento em que Alexandre (outro alter ego do diretor) começa a recitar os intermináveis monólogos retrospectivos sobre os acontecimentos de Maio de 68, com uma dicção culta e articulada, além do gosto por frases de efeito que desafiam o senso comum, sua voz emula os solilóquios de Jerome, em $O$ joelho de Claire (1972). Nesse filme, o protagonista rememora para sua amiga a árdua aventura de tocar no joelho da bela adolescente, numa cena de duração longuíssima, com câmera fixa, e sem qualquer flashback para endossar ou refutar seu ponto de vista.

Nesse sentido, seja pela emulação de temas recorrentes de filmes de seus pares (Le père Noël - Os incompreendidos), seja pela própria fala dos personagens, construídas como uma espécie de contraponto a outras obras do gênero, podemos perceber que tal confecção filmica pode ser vista como uma das várias exposições daquilo que Roland Barthes (2004) entende por intertextualidade e autoria nas obras de arte. Levando em consideração que o texto não estaria preso a uma hierarquia somente de cunho literário, ou numa "simples divisão de gêneros", o teórico nos mostra como todo o texto seria um cruzamento de escrituras múltiplas, "[...] inteiramente tecida de citações, de referências, de ecos: linguagens culturais (que ligam não seria?), antecedentes ou contemporâneas, que o atravessam de fora a fora numa vasta estereofonia" (BARTHES, 2004, p. 70-71). Dessa forma, Barthes (2004) nos permite esclarecer como o processo autobiográfico de Eustache estaria, de alguma forma, ancorado a outros esquemas narrativos do cinema que habitam o seu repertório, num gesto de reconfiguração constante pelo qual essas "mise-en-scènes intertextuais", mais ou menos reconhecidas, são essenciais para objetivar sua própria história de vida. Algo que encontra eco naquilo que o teórico já tinha observado em A preparação do romance, ao comentar um processo parecido entre vida e obra, na recherche de Proust e em Chateaubriand, quando afirma que "não é a obra que se parece com a vida; a escrita conduz" (BARTHES, 2005, p. 173). Escrita essa que parece não estar presa somente ao campo cinematográfico, em Eustache, mas que se torna flexível pela tendência a incorporar outros gêneros discursivos, como o ensaio e o romance.

Apenas para ficar com um caso óbvio, essa postura pode ser retomada nos apurados monólogos de A mãe e a puta (1973), quando Alexandre rememora para Verônika suas aventuras pelas ruas de Paris, no período conturbado de 68. Nessa sequência, a câmera só focaliza o protagonista, captando suas expressões exaltadas, que narra os fatos da época. No momento em que a mise-en-scène busca destacar a habilidade de Alexandre em apresentar verbalmente suas experiências, com a mesma desenvoltura de um romancista que lê a sua obra em voz alta, é interessante perceber como esse filme (assim como outros trabalhos do autor) revela a própria construção do eu como uma espécie de dupla encenação constante.

Dessa forma, ao destacar o elemento de teatralidade nas falas da personagem associada à construção de sua própria imagem, de base biográfica, a partir do empréstimo de outras obras, podemos dizer que essa configuração que pode ser vista como uma das muitas considerações daquilo que Nietzsche (2000) entende por "vida como obra de arte". Para o filósofo, o ser humano deve construir a si próprio, por meio da arte de moldar o seu "eu", a partir de uma rede de referências que o aju- 
dem a recompor sua existência contra um "eu" já constituído:

Enquanto fenômeno estético, a existência conserva-se-nos suportável e a arte dá-nos os olhos, as mãos, e sobretudo a boa consciência que é necessária para poder fazer dela este fenômeno por meio de nossos naturais recursos. É preciso de vez em quando descansarmos de nós próprios, olhando-nos de alto, com o longínquo da arte, para rir ou para chorar sobre nós: é preciso descobrirmos o herói e também o louco que se dissimulam na nossa paixão de conhecer; é preciso sermos felizes, de vez em quando, com a nossa loucura, para podermos continuar felizes com a nossa sageza! (NIETZSCHE, 2000, p. 124)

Talvez o que é mais digno de nota, na citação acima, seja a tentativa de construir para si mesmo uma nova imagem ao arrepio das injunções de um "eu" anterior, na tentativa de enfrentar o destino árduo da existência. Para isso, Nietzsche (2000) aponta que a melhor saída seria a de nos olhar à distância, através de uma perspectiva artística, de criar uma nova subjetividade (ou subjetividades) através do plano da arte, onde o sujeito passaria a experimentar, assim como o trabalho do poeta, novas perspectivas de existir. Sendo a arte um campo vasto de possibilidades a se espelhar, esse sujeito estaria apto a se apropriar dela, em sua totalidade, para moldar esse novo "eu" sempre a devir. Nesse gesto do sujeito tomar distância de si mesmo e estar sempre aberto a novas identificações artísticas, o que fica evidente é como a tendência autobiográfica passa a assumir aqui contornos estéticos mais expressivos, e não somente estando presa à narração de uma história de vida, em termos meramente descritivos. Tal conceito é algo que Leonor Arfuch coloca na pauta do seu livro intitulado 0 espaço biográfico (2010), ao mostrar como determinado texto autobiográfico estaria aberto a identificações com variados modelos narrativos:
São laços identificatórios, catarses, cumplicidades, modelos de herói, 'vidas exemplares', a dinâmica mesma da interioridade e sua necessária expressão pública que estão em jogo nesse espaço peculiar onde o texto autobiográfico estabelece com seus destinatários/leitores uma relação de diferença: a vida como uma ordem, como um devir da experiência, apoiado na garantia de uma existência 'real'. (ARFUCH, 2010, p. 71, grifos da autora)

Como vimos, essa dinâmica está na melhor consonância com o projeto fílmico de Eustache, no momento em que se apropria da linguagem cinematográfica, como um conjunto de intertextos, e raciocina sua própria biografia numa dinâmica de identificação com outros modelos, tanto de narrativa, quanto de vidas exemplares. $\mathrm{Na}$ melhor das hipóteses, é um exercício de interioridade, que parece reescrever parcialmente seu próprio trajeto autobiográfico, onde, consequentemente, se cria uma zona de indiferenciação entre vida e cinema, entre autor e personagens, sendo que uma separação entre biografia e ficção se torna impossivel de sinalizar com segurança.

De fato, a configuração exposta acima encontra muitos pontos de contraste com algumas teorizações feitas por Philippe Lejeune, no seu livro intitulado $O$ pacto autobiográfico (2008). Em certa altura do livro, o autor estipula uma passagem curiosa, na qual afirma que a especificidade autobiográfica está na ancoragem que o sujeito (autor) real faz de si mesmo, reproduzindo com fidelidade uma narrativa de sua história de vida. Nesse árduo processo de definir o que seria a autobiografia, no campo da narrativa - esse espaço em que o eu enunciativo pode aparecer de diversas maneiras -, Lejeune propõe uma saída: "Para que haja autobiografia (e, numa perspectiva mais geral, literatura íntima) é preciso que haja relação de identidade entre o autor, o narrador, e o personagem" (LEJEUNE, 2008, p. 15). O que está em jogo, nesse caso, é a declaração de si mesmo 
como objeto de conhecimento, pelo qual esse autor, ciente da construção de sua própria imagem, declara explícito esse vínculo entre autor, narrador e personagem, numa performatividade em primeira pessoa, encontrando talvez em Confissões de Rousseau (2008), seu exemplo mais ilustrativo. Além disso, para fechar esse ciclo, o teórico transmite parte da responsabilidade para o leitor, transformando-o num juiz que averigua a autenticidade dos fatos, sempre policiando essa tríade autor-narrador -personagem, num ato incontornável e ativo.

No cinema contemporâneo, um exemplo próximo a esse esquema pode ser visto no longa Caro Diário (1993). Aqui, o diretor, Nanni Moretti, além de protagonista, é também o narrador em primeira pessoa, que expõe seus sentimentos sobre fatos do cotidiano, enquanto pesquisa material para o seu novo filme, num road movie confessional. No entanto, podemos observar que o pacto autobiográfico lejeuniano, no repertório de Eustache, não se concretiza de maneira ortodoxa, uma vez que o próprio autor não é protagonista, nem se posiciona como um narrador em primeira pessoa, tanto em ficções quanto em documentários. Para ilustrar tal faceta, dois filmes em sequência são bem expressivos. O primeiro, Le père Noël a les yeux bleus (1966), apresenta uma narrativa que oscila entre a primeira pessoa e a terceira, funcionando como uma crônica adolescente do jovem Daniel (alter ego do diretor) e a sua frustrada tentativa de aproximação com o sexo feminino. No segundo, La Rosière de Pessac (1968), a narrativa rompe com a crônica intimista para dar lugar à câmera impassivel, neutra, que prescinde até da voz em off, habitual em documentários ortodoxos. Sua principal preocupação é a captação da imagem, via planos fixos, que relata a tradicional cerimônia de origens medievais da pequena cidade de Pessac. Em ambos os projetos, percebemos que as marcas do discurso autobiográfico, como a referência à cidade natal do diretor e o uso de reminiscências da juventude, se encontram filtradas por uma narrativa que trata as vivências do "eu" como se fosse uma terceira pessoa, que tenta olhar a si próprio como se fosse um "outro".

Processo esse bem distinto daquele que se dá com Moretti que, num curta subsequente ao Caro Diário - O dia de estreia de Close-up (1996) -, reforça sua persona como uma espécie de Woody Allen italiano. Em oito minutos, retomamos todos aqueles elementos mostrados em Caro Diário, como o seu gosto pelos passeios de lambreta pela cidade, além da sua paixão pelo cinema, quando o enredo focaliza sua preocupação logística com a estreia de Close-up (1990), filme de Abbas Kiarostami, no cinema que administra em Roma.

Portanto, seja pela negação de suas ficções, em primeira pessoa, quando remete a si mesmo como um "ele", seja pela imparcialidade subjetiva de seus documentários, percebemos que Eustache, ao invés de arquitetar uma narrativa coerente, centralizada em torno de uma única identidade, desconstrói-se durante a criação. Longe de ser um ponto negativo, essa singularidade, em sua obra, é efeito do refinamento da linguagem cinematográfica pela experimentação. Seu arranjo e rearranjo dos mais variados tipos de elementos narrativos do cinema é convertido, aqui, como em uma colagem complexa, que inventa seu próprio ritmo autobiográfico. Assim, cria-se uma ampliação dos limites em torno do projeto narrativo de si que, ao mesmo tempo em que sugere outras maneiras de se pensar a autobiografia, exige do espectador uma postura mental diferente, na qual os pontos de coincidência entre vida e obra são tão relevantes quanto os contrastes.

Sem dúvida, é um impasse autobiográfico que gera uma conexão irresistivel com um dos últimos ensaios de Jean Eustache, no qual, 
curiosamente, parece fazer frente a alguns pontos desse imbróglio. No curta Les photos d'Alix (1980), a fotógrafa Alix Cléo Roubaud apresenta suas fotografias experimentais ao inexperiente Boris Eustache, filho do diretor. Entre um lance e outro de fotos, quando a câmera coloca em cena os trabalhos para o expectador, Boris se debruça sobre uma imagem estranha. Tal foto, um negativo ampliado desfocando uma modelo num quarto mal-iluminado, gera uma pergunta do adolescente: "É você?", diz Boris. Alix responde tranquilamente: “Ah, você não deve fazer perguntas como essa. Quer seja eu ou não, todas as fotografias são eu. Mas sim, aqui sou eu". Nesse momento, ela explica qual o tratamento que gerou tal imagem: o uso experimental de sobreposições de uma folha de seu diário pessoal no momento da revelação da película fotográfica, num esforço para mostrar uma fotografia "mais longe do que já é da realidade. E não a realidade, e ainda menos do que a realidade". Ao terminar, ela lança a pergunta: "Você não gostou dessa, não é"? Boris finaliza: "Achei estranha". Essa afirmação feita pela fotógrafa pode ser vista como um eco do próprio processo criativo eustachiano, que passa menos pela busca de uma identidade estável do que pelo reconhecimento do caráter ficcional, em última instância, artístico, de todas as representações do eu.

Além disso, essa foto, assim como outras retomadas durante o curta, dá a impressão de que Alix queira sempre retrabalhá-las, inserindo novos comentários, ressignificando-as a partir da sua composição inicial. Nesse sentido, se pensarmos no efeito distanciador que isso gera, um bom termo de comparação pode ser encontrado no livro de Michel Leiris, $A$ idade viril (2005). Tal obra é um relato da bildung erótica do narrador, que se beneficia de suas incursões na área da antropologia, cuja dicção se dá a perceber no tom, por assim dizer, "mineralizado" da narrativa. Assim como Eustache,
Leiris está menos interessado em recontar sua vida, do início ao fim, do que mapear um padrão de imagens recorrentes que dá estrutura à sua existência, sendo ressignificadas ao longo de sua vida por notas, que retoma fatos escritos da primeira edição. Essa configuração se parece mais com uma montagem alegórica do que com uma narrativa autobiográfica stricto sensu, podendo ser vista como uma espécie de precursor borgeano dos heterogêneos esquemas narrativos de Eustache, nos quais a intimidade de relatar a si mesmo dá lugar aos impasses criados pela reconstrução à distância. Consequentemente, cria-se um efeito muito mais de defasagem do que a eventual coincidência entre os dois eus em jogo.

Assim, ao apostar todas as fichas no efeito de autoestranhamento que esse tipo de representação produz, esse working in progress de Eustache, em filmes como A mãe e a puta e Mes petites amoureuses (1974), está longe de configurar um processo autobiográfico de acordo com as considerações contratuais e referenciais, à maneira de Lejeune. Reconstruir-se, tendo em mente um passado imutável, no qual o eu-biográfico possa ser localizado numa linha histórica, não acontece aqui, porque o passado está sempre sendo ressignificado pelo sujeito do presente, por meio de lembranças que se condensam, se encobrem, e que muitas vezes se tornam falhas. Desnudar uma linha cronológica de uma vida só é possível quando se morre, sendo que essa perspectiva se mantém, como sabemos, desde Édipo Rei, sempre inacessivel ao principal interessado, que, quando tenta recontar a sua história de vida, parece empenhado na tarefa de escrever seu próprio epitáfio. Nesse meio tempo, no hiato que separa o processo da escrita até a chegada da morte, o sujeito paradoxalmente buscaria (re)construir sua identidade através de uma imagem-chave que deveria supostamente funcionar como uma palavra final. 
No entanto, a exemplo de textos como os de Eustache e Leiris (2003), esse ato acaba sendo sempre ressignificado por outro, sem que se possa encontrar um último termo apto a resolver o impasse de vez.

Como bem mostrou De Man, no célebre texto Autobiography as De-facement (1984), é o que responde também pela dificuldade de totalização ligada à configuração autobiográfica tout court, entendida não como uma síntese homônima e contratual, mas antes como um modo de fazer jus à condição em suspenso do eu. Sempre desafiado a fixar os contornos finais de um rosto que pode ser substituído por outro, o efeito encontrado aqui é exatamente de colocar em xeque qualquer ilusão de segurança ou autoconhecimento de si.

Essa configuração autobiográfica, jamais de todo resolvida, em que o eu dá a impressão de ser apenas uma máquina de produzir autoenganos, é um dos efeitos mais interessantes do ganhador do Prêmio Especial do Júri de Cannes, de 1973: A mãe e a puta. Aqui, Eustache nos apresenta um retrato prosaico de uma Paris em crise, pós Maio de 68, numa ambientação que é contextualizada pelos discursos do protagonista Alexandre, personagem que, como bem mostrado no longa, parece ter muitos pontos em comum com o diretor, podendo, por isso mesmo, funcionar como seu alter ego. No entanto, o diretor recusa a empatia fácil com seu protagonista, transformando a câmera num dispositivo silencioso e enigmático, funcionando quase como um psicanalista lacaniano que colhe os relatos do seu paciente. Pelos longos monólogos retrospectivos da vida de Alexandre, é interessante perceber como ele estetiza o seu passado que, por sua vez, faz com que tais monólogos lembrem construções refinadas de um narrador romanesco, tornando sua persona uma figura ao mesmo tempo fascinante e detestável. Tal dinâmica espelha bem a medida da radicalidade autobiográ- fica de Eustache, que parece ser, por muitas vezes, um jogo de repulsas e aproximações dos impasses do eu. Esteta por natureza, Alexandre refaz sua trajetória com informações não confiáveis de si, rumina ideias políticas e culturais de sua geração, de maneira irônica, dando a impressão de querer transformar a sua própria vida numa obra de arte, como deixa claro no monólogo dedicado à sua relação com Gilberte. Num determinado momento ele afirma: “Depois da crise é importante que se esqueça tudo, como a França depois da ocupação, ou depois de Maio de 68. Você está se recuperando como a França depois de Maio de 68 , meu amor". Consequentemente, considerações como essas são recebidas com protestos por sua amante, ao indagar: " $\mathrm{Em}$ que romance você acha que está?". É como se esse "esquecer tudo" e "recuperar-se", em Eustache, fosse convertido em um programa autobiográfico consciente no qual o autor traz para o presente elementos do passado, num gesto em que condensa fatos, restaura vivências em forma de longos solilóquios nos quais, muitas vezes, a ficcionalização de si se sobressai.

Menos comprometido, portanto, com o asfixiante relato de uma vida em percurso e mais aberto a reescritas e reconfigurações constantes, podemos dizer que esse gesto reverbera também no seu programa estilístico como um todo. Isso é insinuado metaforicamente numa cena quando, num restaurante, Verônika pergunta a Alexandre se ela o aborrece. 0 protagonista nada diz e é indagado novamente, com mais uma pergunta: “Quem é você?". Alexandre começa mais um longo monólogo, respondendo à primeira pergunta; diz que não vê problema em aborrecer-se, uma vez que esse sentimento é essencial para a vida, que faz sentido para ele. Ao puxar uma folha de papel do bolso, logo em seguida, ele tenta responder à segunda pergunta, afirmando que fizera um autorretrato. Na folha é mostrado um rascunho, em cujo 
esquema estão escritos os nomes de partes constituintes do rosto de uma pessoa: cabelo, olho, boca, nariz. Alexandre pergunta: "Você me reconhece? É o único certificado de minha existência". Esquema esse que responde pelo seu próprio "fazer cinematográfico", não definindo, a princípio, uma face própria, mas que prefere antes deixá-la em aberto. Gradativamente, por meio da pesquisa formal, incorpora os mais variados estilemas do cinema, em cada projeto, define-se um rosto próprio, orgânico, que corresponde a uma espécie de síntese das mais variadas escolas: do realismo de Jean Renoir até modelos contemporâneos ao autor, como a nouvelle vague e o nouveau cinèma.

Não por acaso, essa disposição de incorporar os mais diversos tipos de materiais heterogêneos do cinema encontra muito daquilo que Philippe Gasparini (2014, p. 189) afirma, ao comentar sobre as considerações de Lejeune, no texto "Autoficção é o nome de quê?", quando diz que "a autobiografia emprega todos os procedimentos romanescos de seu tempo". Num processo análogo, Eustache parece se servir bem dessa tendência, buscando, nos estudos contemporâneos sobre o Cinema de Poesia de Pasolini, de 1965, material para confeccionar seu filme subsequente: Mes petites amoureuses (1974). Nesse projeto, ao contrário da narrativa fria e distanciada, em terceira pessoa, de $A$ mãe e a puta, aqui ela oscila constantemente entre a primeira e a terceira pessoa. Para Pasolini (1981), essa variação obsedante entre as duas instâncias (1a e 3a pessoas) é um modo de fazer jus às meditações subjetivas de determinado autor, por meio de metáforas e sistemas de signos variados, sendo que sua personalidade é convertida no drama encenado, ora pelo protagonista, quando configura um monólogo interior, ou pela própria mise-en -scène. Isso é bem visível, no filme em questão,

1 Lejeune, citado por Philippe Gasparini, em Ensaios sobre a autoficção. Belo Horizonte: Editora UFMG, 2014. quando o ritmo narrativo obedece, em grande parte, ao ponto de vista do protagonista, emoldurado por cenas fragmentadas, narradas por uma voz em off, que funciona como pequenos aforismos, numa performatividade análoga a relatos de um diário íntimo. Sem dúvida, é uma estratégia destoante da figuração heterogênea e aberta de seus outros trabalhos, sendo que, aqui, a narrativa apresenta um relato mais intimista e confessional, um retorno às memórias da infância do diretor. Luc Moullet (2000) coloca bem em perspectiva esse aspecto, quando comenta que a principal obsessão de Eustache, nesse projeto, era reconstruir sua infância pela mise-en-scène subjetiva, onde cada parede, cada árvore e cada cômodo, cada um deles lembraria sua vida rotineira na cidade natal de Pessac; ou seja, um olhar do presente em direção ao passado.

É o que vemos no longa em questão, quando acompanhamos a rotina de seu alter ego Daniel, transitando da sua infância à adolescência, cujas descobertas e embates com a aspereza do mundo são as principais linhas de força do filme. Inicialmente, ele vive uma vida agradável em Pessac, onde sua rotina se resume ao trajeto da escola à casa de sua avó. A pretexto de continuar os estudos, ele deve mudar de cidade e deixar todo o seu círculo social para viver uma nova vida, com sua mãe e seu padrasto em Narbonne. Nesse ambiente bastante distinto do anterior, a narrativa vai mostrando como, pouco a pouco, se constitui a impossibilidade do protagonista estabelecer relações com sua nova família, no momento em que Daniel percebe que seus pais têm planos diferentes do que ele esperava. Uma cena que poderia sintetizar tudo isso, servindo como ponto de partida no qual o personagem construirá sua identidade, se dá quando, ao final das férias escolares, Daniel comenta com sua mãe sobre suas expectativas de continuar os estudos na nova cidade. No entanto, esses 
planos são solapados por completo, quando ela diz que não pode arcar com as despesas escolares e que ele deveria preencher seu tempo livre com algum trabalho. Essa afirmação, lançada num tom impassivel, por ela, é recebida como um choque, por Daniel, que entende claramente que a dificuldade em questão passa menos pela falta de recursos e mais pelo interesse de seus pais o usarem como força de trabalho e exploração. Provavelmente, o ponto decisivo da narrativa ocorre quando a câmera dá atenção ao rosto do protagonista, recebendo a notícia, para logo em seguida, sem qualquer reação, desaparecer em fade out, lentamente. Essa imagem pode ser vista como a figuração da própria rejeição e desafeto que o protagonista sofre, tornando-se um desadaptado por natureza.

É como se tal face em fade, ao mesmo tempo em que pudesse ser lida como uma espécie de anamnese de suas obsessões autobiográficas, servisse também como metáfora do apagamento subjetivo do próprio Eustache, em vários alter egos. Daquele instante em diante, Eustache se aventuraria mascarado - Daniel, Alix, Alexandre - sendo que, cada nova desfiguração, proporcionaria uma tentativa de se

\section{Referências}

ARFUCH, Leonor. 0 espaço biográfico: dilemas da subjetividade contemporânea. Tradução de Paloma Vidal. Rio de Janeiro: EdUERJ, 2010.

BAECQUE, Antoine de. Cinefilia: a invenção de um olhar, história de uma cultura. Tradução de André Telles. São Paulo: Cosac Naify, 2010.

BARTHES, Roland. 0 rumor da língua. Tradução de Mário Laranjeira. São Paulo: Martins Fontes, 2004.

A preparação do romance II: a obra como vontade. Tradução de Leyla Perrone-Moisés. São Paulo: Martins Fontes, 2005.

DE MAN, Paul. Autobiography as De-facement. In: compor em etapas, isolando traços mais definidores do que simplesmente se pintar ao natural, em um único projeto. Por esse motivo, o eu, em sua filmografia, seria uma espécie de desafio de recomposição, da tentativa de se definir parcialmente, em fragmentos, para construir uma autobiografia fora do convencional, em que as possibilidades são tão importantes quanto os fatos consumados, e os lugares da vida e da arte estão, o tempo todo, se contagiando e se retroalimentando.

Essa estratégia encontra ecos naquilo que Luc Moullet (2000) sugeria, ao mencionar que os filmes de Eustache, da fase dos anos de 1970, instituem um jogo com o espectador, que deve lutar indefinidamente para encontrar algum sentido naquilo que o autor oculta. Indefinição que, longe de ser um ponto negativo, parece ser um dos traços mais interessantes do autor em questão, ao se recusar a todo o momento em levar o espectador do ponto $A$ ao ponto $\mathrm{B}$, com a finalidade de mostrar uma história de vida, preferindo antes adiar a última palavra sobre si mesmo em filmes que, da vida como obra de arte ao Cinema de Poesia, representam um dos exemplos autobiográficos mais interessantes do cinema moderno.

The rhetoric of romanticism. New York: Columbia University Press, 1984. p. 67-81.

DIAS, Rosa Maria. Nietzsche, vida como obra de arte. Rio de Janeiro: Civilização Brasileira, 2011.

EUSTACHE, Jean. La maman et la putain. Youtube, 24 de set. de 2014. Disponivel em: <https://www.youtube.com/watch?v=Q12zgo39ovg>. Acesso em: 26 jun. 2015.

. Les photos d'Alix. Youtube, 19 de jan. de 2012. Disponivel em: <https://www.youtube.com/ watch?v=96LmSyvluJU>. Acesso em: 26 jun. 2015.

. Le père Noël a les yeux bleus. Youtube, 09 
de fev. de 2014. Disponivel em: <https://www.youtube.com/watch?v=Xfo705Tc/1k>. Acesso em: 26 jun. 2015.

. Mes petites amoureuses. Youtube, $15 \mathrm{de}$ nov. de 2013. Disponivel em: <https://www.youtube.com/watch?v=DYnzr wVn9s>. Acesso em: 26 jun. 2015.

GASPARINI, Philippe. Autoficção é o nome de quê? In: Ensaios sobre a autoficção. Tradução de Jovita Maria Gerheim Noronha. Belo Horizonte: Editora UFMG, 2014. p. 181-221.

LEIRIS, Michel. A idade viril: precedido por Da literatura como tauromaquia. Tradução de Paulo Neves. São Paulo: Cosac \& Naify, 2003.

LEJEUNE, Philippe. 0 pacto autobiográfico: de Rousseau à internet. Belo Horizonte: Editora UFMG, 2008.

MOULLET, LUC. Melhor queimar-se do que fenecer:
Jean Eustache, o dândi proletário. 2000. Disponível em: <http://www.focorevistadecinema.com.br/ FOCO4/eustachemoullet.htm>. Acesso em: 26 jun. 2015.

NIETZSCHE, Friedrich. A gaia a ciência. Tradução de Alfredo Margarido. Lisboa: Guimarães Editores, 2000.

PASOLINI, Pier Paolo. Empirismo herege. 2. ed. Lisboa: Assírio \& Alvim, 1981.

PHILIPPON, Alain. Jean Eustache. Paris: Cahiers du Cinéma, 2005.

ROUSSEAU, Jean-Jacques. Confissões. Tradução livros I a X Rachel de Queiroz, livros XI e XII José Benedicto Pinto. Bauru, SP: EDIPRO, 2008.

Recebido em: 05.05.16

Aprovado em: 20.07.2016

Romero Fidelis de Souza Maciel é mestrando em Estudos da Linguagem na linha de pesquisa Memória e Linguagem Cultural, pela Universidade Federal de Ouro Preto, e especialista em Revisão de Textos pela PUC Minas. Atualmente, desenvolvo pesquisas na área da linguagem cinematográfica, em comparação com narrativas literárias.

E-mail: romerofideliz@gmail.com.

Rua Santa Teresa, 166A, Bairro Bandeirantes - Mariana-MG CEP: 35420-000 